\title{
Pore Pressure at Plate Boundaries: Insights from Modeling
}

by Demian Saffer

\section{Introduction}

Fluids play a key role in a wide range of mechanical and transport processes in the Earth's crust. Fluid flow can efficiently redistribute heat and solutes; as a result, fluid assisted transport and fluid rock interaction are important controls over the rate and extent of metamorphism, precipitation, and sealing of fractures. Fluid-rock reaction and precipitation impact permeability and fault strength (Chester et al., 1993). In addition to its chemical effects, pore fluid mediates the strength of brittle rocks because pore pressure controls effective stress (Hubbert and Rubey, 1959). In particular, elevated pore fluid pressure has been invoked as a cause of mechanical weakness along plate boundary faults and within the surrounding crust, at subduction zones (Davis et al., 1983) and along continental transforms (Irwin and Barnes, 1975). Because fluid pressure is central to a host of hypotheses explaining apparent fault weakness, direct measurements and indirect constraints on fluid pressure and flow are high priorities for fault zone drilling.

Numerical models provide key tools to link observations at shallow depths or the surface with borehole observations, and to test hypotheses generated on the basis of such data. These efforts can complement deep drilling by helping to direct measurement strategies, and by estimating pressures and flow patterns at depths and over a larger spatial extent than reached by drilling. In the context of understanding fluid pressure at plate boundaries, modeling efforts have provided insights into many fundamental questions, including: What are the magnitudes and spatial patterns of suprahydrostatic pore pressure? What controls pore pressure, and how should it vary-systematically between margins or with depth? Are hypothesized fluid sources sufficient to generate fault-weakening overpressures? What role do permeable zones (faults, sands) play in drainage, and in localizing pressure or flow?

Here I summarize three studies in which hydrologic models are combined with available data to better understand pore pressure and its mechanical effects at plate boundaries (Table 1). In the first example, field and laboratory data constrain a simple analytic model, which elucidates fluid flow patterns and controls on pore pressure buildup during initial loading at subduction zones. In the second example, regional scale numerical models are used to quantify the influence of fundamental geologic factors on pore pressure, and consequently on rock strength, in subduction zones. In the third example, models are used to evaluate hypotheses for pore pressure generation and compartmentalization invoked to explain mechanical weakness along the San Andreas fault system in central California.

\section{Example 1: Simple Model for Dewatering at the Toe of Subduction Margins}

At subduction zones, as incoming sediments are offscraped or underthrust at the trench, elevated pore pressures result from rapid loading of low-permeability sediment (Table 1). Pore pressure within the sediment underthrust at the trench is especially important for the mechanical strength of the plate boundary fault system, because the main décollement localizes immediately above this sediment, and at many margins downsteps into the section within a few to tens of kilometers from the trench. Along transects where Ocean Drilling Program (ODP) drilling has penetrated the underthrust section at the Nankai, northern Barbados, and Costa Rican subduction zones, it maintains anomalously high porosity for its burial depth, suggesting under-consolidation and associated high fluid pressure. Quantitative estimates of in situ pore pressure have been obtained from laboratory consolidation tests on core samples, and from observed compaction trends both in boreholes and inferred from seismic data (Screaton et al., 2002; Tobin and Saffer, 2003). At all three margins, the different methods yield consistent results and indicate development of overpressures that increase systematically with distance from the trench. Estimated pore pressures suggest nearly undrained conditions at the base of the section (excess pressures equal to the load emplaced by subduction burial) and partially drained conditions at the top.

To first order, the data can be explained by a simple model describing a layer subjected to a continuously increasing load, in which fluid escapes upward to a free surface (Wissa et al., 1971; Fig. 1). In the model, pore pressure varies systematically with distance from the trench and depends upon the thickness of the consolidating sediment layer $(H)$, the permeability and compressibility of the sediment layer (described by a single variable, $\left.C_{v}\right)$, and the plate convergence rate $\left(v_{p}\right)$. For each margin, laboratory measurements constrain sediment permeability and compressibility. Notably, $v p, H$, and $C v$ are different for each of the three locations, yet all of the data are consistent with a generic model in which degree 
Table 1. Parameters of 2-D numerical models of subduction zones.

\begin{tabular}{llll} 
Example & Model Source Terms & Scale & Permeability \\
\hline $\begin{array}{l}\text { Subduction zones (toe) } \\
\text { Loading by underthrusting } \\
\text { (virtual) }\end{array}$ & 100 's of $\mathrm{m}$ & $\begin{array}{l}\text { Sediment permeability measured in laboratory, function of } \\
\text { porosity }\end{array}$ \\
$\begin{array}{l}\text { Subduction zones } \\
\text { (regional) }\end{array}$ & $\begin{array}{l}\text { Prescribed porosity loss based } \\
\text { on drilling and seismic data }\end{array}$ & 10 's of km & $\begin{array}{l}\text { Sediment permeability measured in laboratory, function of } \\
\text { porosity; range of fault permeabilities explored }\end{array}$ \\
$\begin{array}{l}\text { San Andreas Fault } \\
\text { System }\end{array}$ & $\begin{array}{l}\text { Fluid release by prograde } \\
\text { metamorphism }\end{array}$ & $\sim 10 \mathrm{~km}$ & Function of depth; range of fault permeabilities explored \\
\hline
\end{tabular}

of under-consolidation depends on the relative magnitudes of loading rate, drainage path length, and sediment hydraulic properties (Fig. 1). The agreement between observation and model implies that upward drainage to a highly permeable décollement dominates dewatering to distances of at least 5-10 $\mathrm{km}$ landward of the trench. The model results also suggest that severe under-consolidation should persist for tens of kilometers from the trench (Saffer, 2007).

\section{Example 2: Regional Scale Hydrologic Models of Subduction Complexes}

In several studies, 2-D numerical models of subduction zones have been used to estimate pore pressures and test hypotheses about the nature of fluid flow at the regional scale (tens of kilometers; Bekins et al., 1995; Screaton et al., 1990). In these models, pore pressure and flow are driven by sediment compaction (Table 1). Fluid sources from compactive dewatering are incorporated at each node within the model domain, and are constrained by porosity data from boreholes and inferred from seismic velocity data (these models are described in detail by Bekins and Dreiss, 1992; see also Screaton et al., 1990). Sediment bulk permeability in the models is constrained by laboratory data, and a range of fault zone permeability has been investigated. Fault permeability is typically assumed to be higher than that of the sediment matrix, based on observations of (1) fluid expulsion at the seafloor and (2) chemical and thermal anomalies centered on faults. For several well studied margins, modeled pore pressure is in excellent agreement with that measured in borehole observatories (Barbados; Bekins and Screaton, 2007) and estimated by methods described in the previous example (Nankai and Costa Rica; Spinelli et al., 2006; Tobin and Saffer, 2003).
Regional scale models have also been used to evaluate the relative importance of factors that control pore pressure and ultimately the taper angle of subduction accretion complexes. The factors include sediment and fault permeability, incoming sediment thickness, convergence rate, and partitioning of sediment between accretion and underthrusting. By isolating and quantifying the influence of each of these factors on pore pressure, a comprehensive sensitivity analysis provides a basic framework for considering observations from active subduction complexes. As in the case of burial at the toe of subduction systems described above, the results show that pore pressure in accretionary wedges can be viewed as a balance between factors which drive pore pressure (source terms) and those that limit flow (permeability and drainage path length). Sediment permeability and incoming sediment thickness are most important, whereas fault permeability and the partitioning of sediment have small effects (Fig. 2).

By combining the hydrologic model with critical taper theory, systematic relationships emerge between the fundamental factors that govern fluid pressure and stable taper angle (Saffer and Bekins, 2006). For example, as sediment permeability is increased, modeled pore pressure decreases and allows taper angles to steepen. With increased sediment thickness, increased pore pressure drives a decrease in taper angle (Fig. 2). In general, low permeability and thick incoming sediment sustain high pore pressures consistent with shallowly tapered geometry, whereas high permeability and thin incoming sediment should result in steep geometry. The model results compare favorably with available data from active accretionary complexes-active margins characterized by a significant proportion of fine-grained sediment within the incoming section (such as the northern Barbados Trench and the eastern Nankai Trough) exhibit thin taper
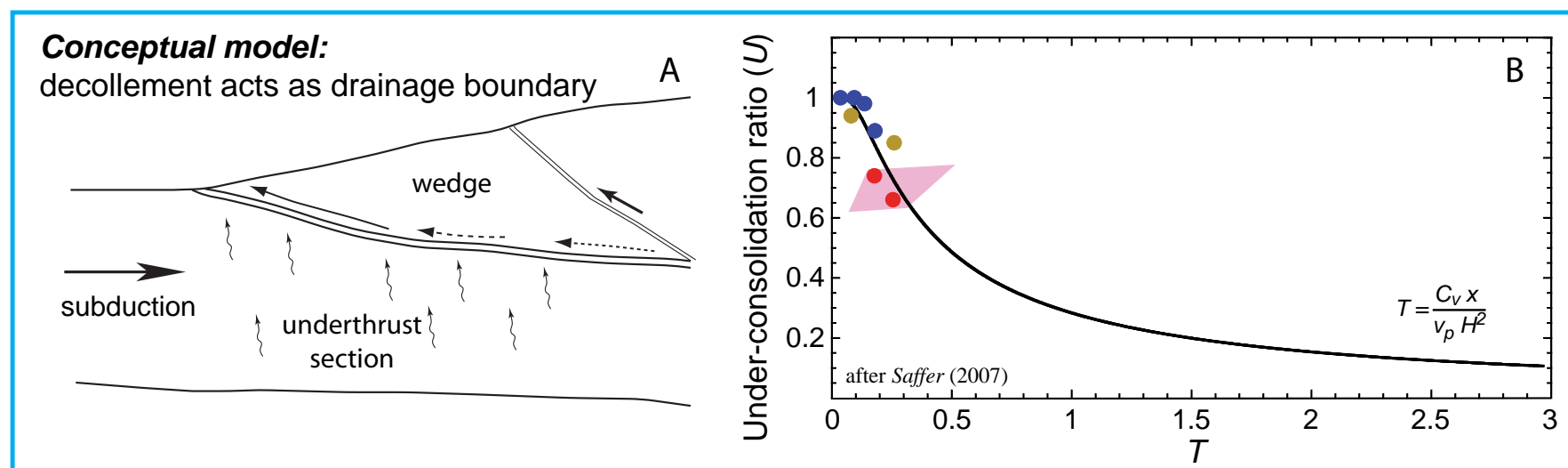

Figure 1. [A] Schematic showing drainage pattern for 1-D consolidation model. [B] Modeled under-consolidation ratio, U, vs. dimensionless time (solid black curve); mean values of $U$ from ODP sites at Barbados (blue), Nankai (red) and Costa Rica (tan), and inferred from seismic velocity data at Nankai (pink shaded region). 

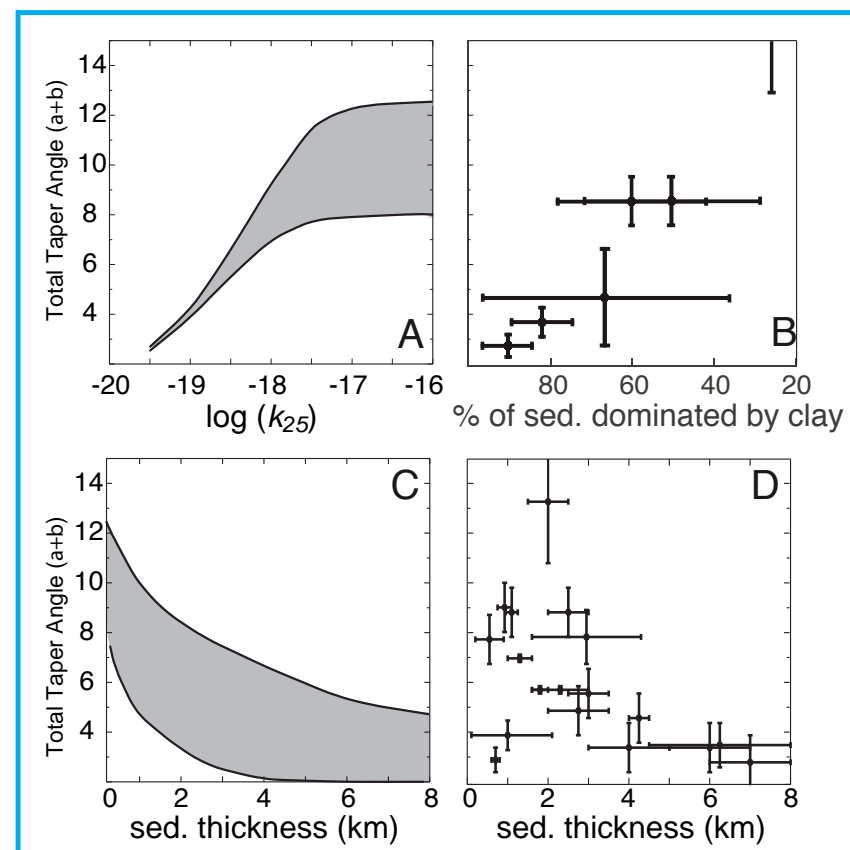

Figure 2. [A] Model results showing influence of permeability (plotted as log permeability at $25 \%$ porosity) on taper angle of accretionary wedges. [B] Data from active accretionary complexes where drilling has documented lithologies of incoming sediment, showing relationship between proportion of clay in sediment and taper angle. [C] Model results. [D] Data from active accretionary complexes, showing influence of sediment thickness on taper angle. After Saffer and Bekins (2006).

angles, whereas those characterized by a higher proportion of sandy turbidites (such as Cascadia, Chile, and Mexico) have steep taper angles. Observations from active margins also indicate a strong trend of decreasing taper angle with increased sediment thickness. One key implication is that hydrologic properties should strongly influence the strength of the crust in a wide range of geologic settings.

\section{Example 3: A Test of Hypotheses Along the San Andreas Fault System}

Along the San Andreas fault in California, heat flow observations and inferred stress orientations have been interpreted to indicate that the fault moves under considerably smaller shear stresses than predicted by laboratory-derived values for rock friction (Zoback et al., 1987). Elevated fluid pressures are one likely candidate to explain the apparent fault weakness - such overpressures may be either regionally extensive resulting in a weak fault embedded within a weak crust (Hardebeck and Hauksson, 2000), or localized along the fault resulting in a weak fault embedded within a strong crust (Zoback et al., 1987). Several hypotheses have been proposed to explain the generation of fluid pressure in the vicinity of the fault. In the study summarized here, Fulton et al. (2005) used numerical models to investigate (1) whether fluid produced by prograde metamorphism of the Franciscan assemblage is a likely candidate for generating significant and lasting overpressures along the fault system, and (2) if so, whether overpressures can be localized along the fault.

The apparent correlation between $\mathrm{CO}_{2}$ discharge, ${ }^{18} \mathrm{O}$ enrichment, geologic structure, and observed seismicity patterns originally led Irwin and Barnes (1975) to suggest that fluids of metamorphic origin sourced from dehydration of Franciscan rocks are trapped and forced into the fault zone, causing fluid overpressures in areas where overlying low permeability Great Valley sediments and serpentinite act as a barrier to upward fluid expulsion. Fulton et al. (2005) quantitatively tested this hypothesis using a two-step approach. First, the spatial and temporal distribution of fluid sources from prograde dehydration was estimated from theoretical values of whole-rock $\mathrm{H}_{2} \mathrm{O}$ content and P-T histories for the Franciscan crust in the wake of northward migration of the Mendocino Triple Junction (MTJ) (Table 1). Second, the fluid sources were incorporated into transient 2-D models of fluid flow within cross sections perpendicular to the fault. In the models, permeability of the Salinian and Franciscan crust was constrained by the work of Ingebritsen and Manning (1999) and assumed to decrease logarithmically with depth. In addition to a 500-m-thick low-permeability serpentinite body $\left(\mathrm{k}=10^{-20} \mathrm{~m}^{-2}\right)$ extending across the eastern half the model domain at a depth of $2 \mathrm{~km}$, model simulations also explore a range of fault permeability architectures including a fault barrier, a fault conduit, and a combined conduit-barrier.

For models that incorporate both a serpentinite cap and fault barrier, overpressures as large as $62 \%$ of lithostatic pressure develop within $4 \mathrm{My}$ of MTJ passage (a region extending $\sim 200 \mathrm{~km}$ south of the present day location of the MTJ), where sources are abundant. However, simulated pressures dissipate within several thousand years because fluid sources die out due to stabilization in temperature and the low remaining $\mathrm{H}_{2} \mathrm{O}$ content in lower crustal rocks. Overall, the presence of a low permeability cap can enhance regional overpressure development; however, none of the structures investigated allowed overpressures to localize along the fault (Fig. 3). The results suggest that metamorphic dehydration within the Franciscan crust has the potential to cause regional overpressure and weakening of the crust for

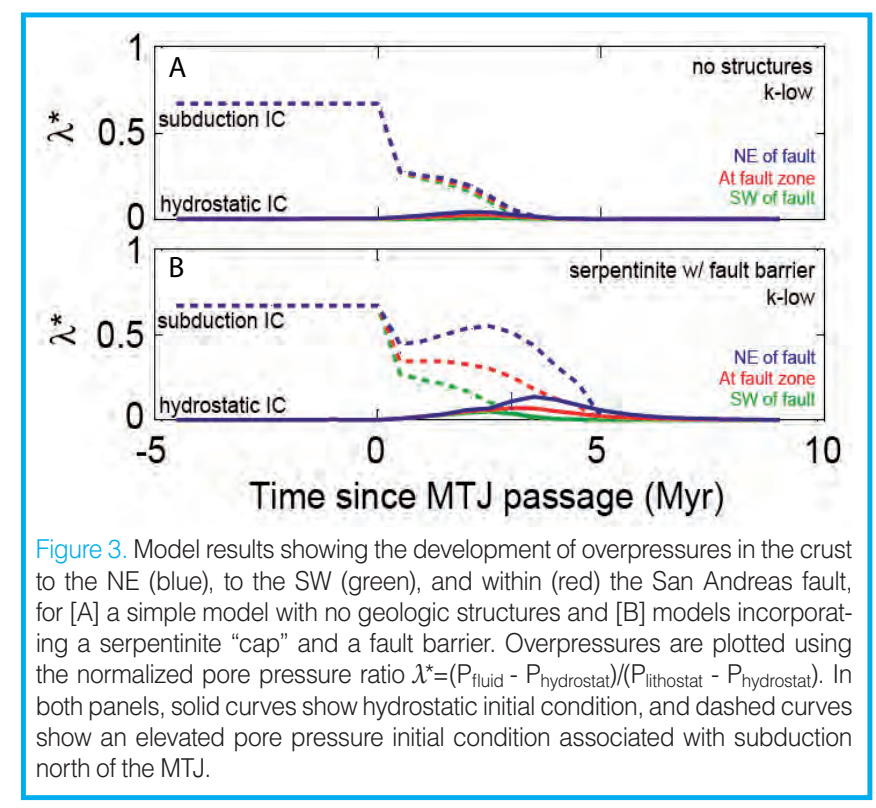


$\sim 4 \mathrm{Ma}$ after MTJ passage, currently encompassing a region $\sim 200 \mathrm{~km}$ south of the MTJ, but is limited as a sole mechanism for long-term weakening of the San Andreas fault along much of its length because overpressures cannot be sustained or localized along the fault.

\section{Summary}

In the examples summarized above, the integration of hydrologic modeling with datasets enabled by drillingincluding laboratory studies on core samples and down-hole measurements-has provided insight into first-order questions about the magnitude, distribution, and mechanisms of elevated pore pressure in tectonically active environments. However, the utility of such models is closely tied to the availability of key datasets. Although data from the land surface (or seafloor) are important, drilling provides the most powerful and direct constraints on pore pressure and fluid flow in the subsurface. In particular, the hydraulic properties of faults and wall rock at relevant scales are key unknowns in most models; down-hole and long-term perturbation tests are one effective way to constrain these quantities. Likewise, rock sampling and geochemical data are critical toward better defining the fluid source terms that drive flow in these dynamic environments. Down-hole pressure and temperature measurements provide key data to test flow models. In this context, fault zone drilling in conjunction with surface measurements will provide vital data to clarify the role of fluids in faulting and to more definitively test hypotheses for fluid pressure development and its mechanical and chemical effects.

\section{References}

Bekins, B. and Screaton, E., 2007. Pore pressure and fluid flow in the northern Barbados accretionary complex. In Dixon, T., Moore, C. J., Eds. The Seismogenic Zone of Subduction Thrusts, New York (Columbia University Press), 148-170.

Bekins, B.A. and Dreiss, S.J., 1992. A simplified analysis of parameters controlling dewatering in accretionary prisms. Earth Planet. Sci. Lett., 109:275-287, doi:10.1016/0012821X(92)90092-A.

Bekins, B.A., McCaffrey, A., and Dreiss, S.J., 1995. Episodic and constant flow models for the origin of low chloride waters in a modern accretionary complex. Water Resour. Res., 31:3205-3215, dodi:10.1029/95WR02569.

Chester, F.M., Evans, J.P., and Biegel, R.L., 1993. Internal structure and weakening mechanisms of the San Andreas fault. $J$. Geophys. Res., 98:771-786.

Davis, D., Suppe, J., and Dahlen, F.A., 1983. Mechanics of fold-andthrust belts and accretionary wedges. J. Geophys. Res., 88:1153-1172.

Fulton, P.M., Saffer, D.M., and Bekins, B.A., 2005. Crustal dehydration and overpressure development on the San Andreas fault. Eos Trans. AGU, 86(52), Fall Meet. Suppl., Abstract T43C02 .

Hardebeck, J.L. and Hauksson, E., 2000. The San Andreas fault in southern California: A weak fault in a weak crust. In Kovach,
R. (Ed.), Proceedings of the 3rd Conference on Tectonic Problems of the San Andreas Fault System, September 6-8, 2000, Stanford University.

Hubbert, M.K. and Rubey, W.W., 1959. Role of fluid pressure in mechanics of overthrust faulting. Geol. Soc. Am. Bull., 70:115-166, doi:10.1130/0016-7606(1959)70[115: ROFPIM]2.0.CO;2.

Ingebritsen, S.E. and Manning, C.E., 1999. Geological implications of a permeability-depth curve for the continental crust. Geology, 27:1107-1110, doi:10.1130/00917613(1999) 027<1107:GIOAPD >2.3.CO;2.

Irwin, W.P. and Barnes, I., 1975. Effect of geologic structure and metamorphic fluids on seismic behavior of the San Andreas Fault system in central and northern California. Geology, 3:713-716, doi:10.1130/0091-7613(1975)3<73: EOGSAM $>2.0 . \mathrm{CO} ; 2$

Saffer, D.M., 2007. Pore pressure within under thrust sediments in subduction zones. In Dixon, T., Moore, C. J., Eds., The Seismogenic Zone of Subduction Thrusts, New York (Columbia University Press), $692 \mathrm{p}$.

Saffer, D.M. and Bekins, B.A., 2006. An evaluation of factors influencing pore pressure in accretionary complexes: Implications for taper angle and wedge mechanics. $J$. Geophys. Res., 111:B04101, doi:10.1029/2005JB003990.

Screaton, E.J., Wuthritch, D.R., and Dreiss, S.J., 1990. Permeabilities, fluid pressures, and flow rates in the Barbados ridge complex. J. Geophys. Res., 95 :8997-9007.

Screaton, E.J., Saffer, D.M., Henry, P., Hunze, S., and the Leg 190 Shipboard Scientific Party, 2002. Porosity loss within underthrust sediment of the Nankai accretionary complex: Implications for overpressures. Geology, 30:19-22, doi:10.1130/0091-7613(2002)030<0019:PLWTUS>2.0.CO;2.

Spinelli, G., Saffer, D.M., and Underwood, M.B., 2006. Hydrogeologic responses to three-dimensional temperature variability, Costa Rica subduction margin. J. Geophys. Res., 111:B04403, doi:10.1029/2004JB003436.

Tobin, H.J. and Saffer, D.M., 2003. Fluid pressure in the shallow plate interface at the Nankai Trough subduction zone. Eos Trans. $A G U, 84$ (46), Fall Meet. Suppl., Abstract T41A-04.

Wissa, A.E.Z., Christian, J.T., Davis, E.H., and Heiberg, S., 1971. Consolidation at constant rate of strain, J. Soil Mech. Found. Div., ASCE, 97(SM10):1393-1413.

Zoback, M.D., Zoback,M.L., Mount, V.S., Suppe , J., Eaton, J.P., Healy, J.H., Oppenheimer, D., Reasenberg, P., Jones, L., Raleigh, C.B., Wong, I.G., Scotti, O., and Wentworth, C., 1987. New evidence on the state of stress of the San Andreas Fault, Science, 238:1105-1111, doi:10.1126/science.238.4830.1105.

\section{Author}

Demian Saffer, Department of Geosciences, The Pennsylvania State University, 310 Deike Building, University Park, Pa. 16802, U.S.A., e-mail: dsaffer@geosc.psu.edu. 